\title{
Plan spawania dźwigara wiaduktu kolejowego
}

\author{
A plan of welding the railway viaduct girder
}

\section{Streszczenie}

Przedstawiono plan spawania dotyczy wykonania konstrukcji dźwigara wiaduktu kolejowego w klasie EXC 4 wg PN -EN 1090-2. Omówiono połączenia śrubowe oraz wymagania dotyczące ich wykonania. Przedstawiono kontrolę przed, podczas i pospawaniu oraz zamieszczono plan badań. Określono kolejność spawania poszczególnych zespołów dźwigara. Przedstawiono wymagania dotyczące dokumentacji końcowej.

Słowa kluczowe: spawanie; plan spawania; dźwigar; kontrola spawania

\section{Abstract}

A welding plan connected with manufacturing the construction of the railway viaduct girder of the EXC 4 rate according to PN-EN 1090-2 standard is presented. Bolt couplings and their requirements are provided in the article. Welding control before, during and after the welding process is given as well as the testing plan. An order of welding specific units of the girder is shown. Requirements relating to the final documentation is given.

Keywords: welding; a plan of welding; girder; welding control

\section{Wstęp}

Prezentowany plan spawania dotyczy wykonania konstrukcji dźwigara wiaduktu kolejowego w klasie EXC $4 \mathrm{wg}$ PN-EN 1090-2 widocznego na rysunku 1 - widok z góry, rysunku 2 - widok z boku, rysunku 3 - przekrój oraz rysunku 4 - przekrój na podporze. Całościowo inwestycja składa się z czterech wiaduktów kolejowych o łącznej liczbie 38 dźwigarów. Materiałem podstawowym zgodnie z dokumentacją techniczną jest stal konstrukcyjna S355J2+M (belki HL $1000 \times 642$ ) oraz $355 \mathrm{~J} 2+\mathrm{N}$ (pozostałe pozycje konstrukcji) zgodnie z EN10025-2.Dodatkowo blachy oznaczone na rysunkach warsztatowych symbolem pioruna należy zbadać na rozwarstwienie za pomocą badań ultradźwiękowych zgodnie zEN10160/10306 przez wykwalifikowany personel (stopień 2 wg PN-EN ISO 9712).

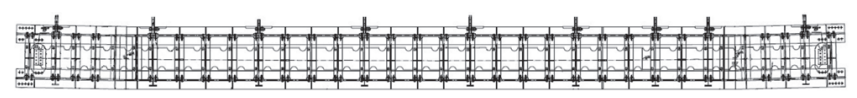

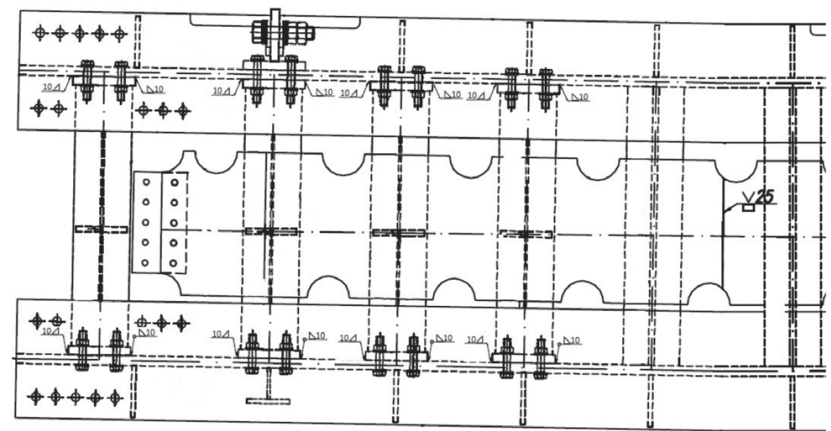

Rys. 1. Widok dźwigara wiaduktu kolejowego z góry

Fig. 1. A view of the railway viaduct girder from the top
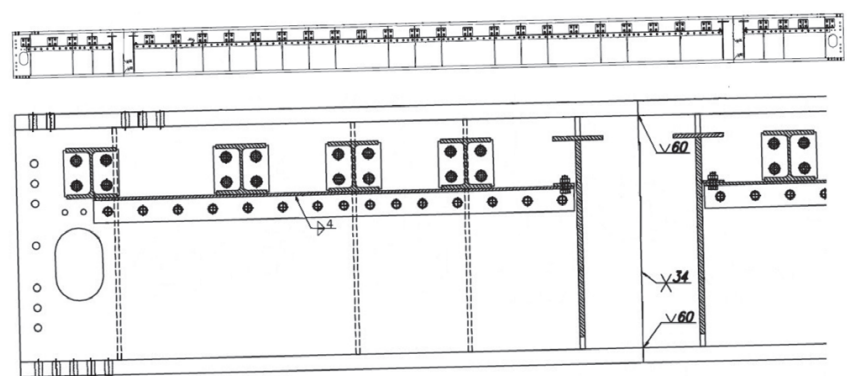

Rys. 2. Widok dźwigara wiaduktu kolejowego $z$ boku

Fig. 2. A view of the railway viaduct girder from the side

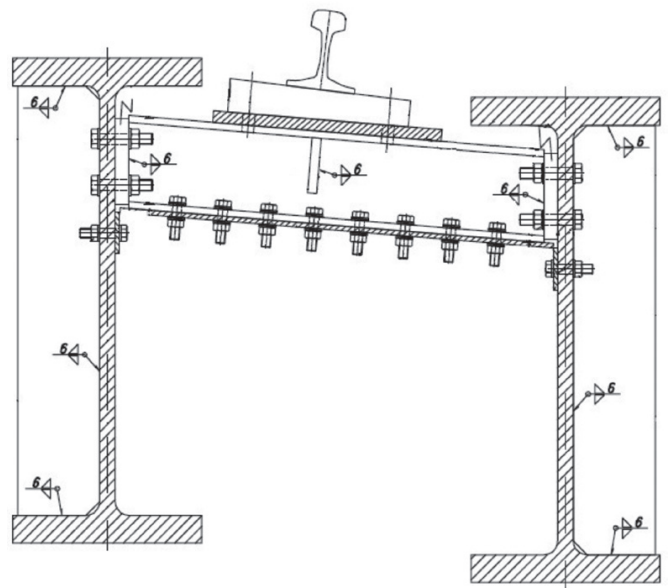

Rys. 3. Widok dźwigara wiaduktu kolejowego w przekroju

Fig. 3. A view of the railway viaduct girder in the cross-section

Dr hab. Inż. Jacek Słania, prof. PCz - Politechnika Częstochowska; mgr inż. Karol Rafalski - Mostostal Puławy S.A. Autor korespondencyjny/Corresponding author: jacek_slania@poczta.onet.pl 


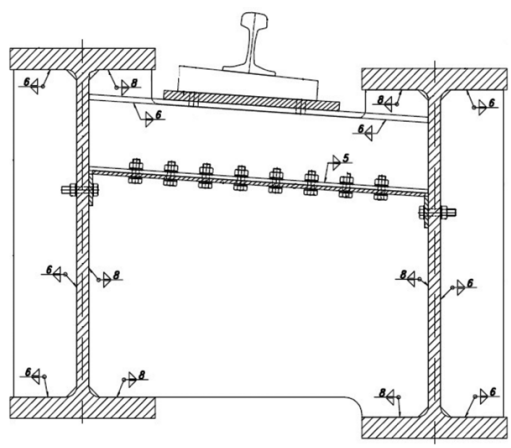

Rys. 4. Widok dźwigara wiaduktu kolejowego w przekroju na podporze Fig. 4. A view of the railway viaduct girder in the cross-section on the support

\section{Połączenia śrubowe}

W czterech wiaduktach kolejowych znajduje się ponad 40000 połączeń śrubowych. Otwory powinny być wykonane poprzez wiercenie, które występują zarówno w kształtownikach jak i blachach. Aby wykonać w bardzo krótkim czasie taką ilość otworów użyto systemu wiercącego CNC. Wykaz materiałów złącznych (śrub, nakrętek i podkładek) znajduje się w tablicy I.

Przed przystąpieniem do montażu połączeń śrubowych należy:

- oczyścić powierzchnie od wszelkich zanieczyszczeń (olej, farba, rdza itp.) oraz od zadziorów, które mogą uniemożliwić ścisłe przyleganie powierzchni łączonych,

- sprawdzić oznaczenie cech wytrzymałościowych na śrubach, nakrętkach i podkładkach oraz stan ich powierzchni,

- dokręcić śruby w połączeniach niesprężanych do stanu ścisłego docisku gdzie klucz udarowy zaczyna drżeć (podczas kontrolnego ostukiwaniu młotkiem dokręconej śruby żadne z zestawu połączenia śrubowego nie powinno przesuwać się ani drgać),

- dokręcanie śrub w połączeniach sprężanych (HV) wykonywać przez obrót nakrętki uzyskując określoną siłę sprężania używając klucza dynamometrycznego, dzięki któremu można odczytać moment dociągający (klucz dynamometryczny powinien posiadać aktualne świadectwo kalibracji).

Wartości momentu dokręcającego dla poszczególnych połączeń śrubowych przedstawiono $\mathrm{w}$ tablicy II.

\section{Przygotowanie i kontrola przed spawaniem obejmuje}

- kompletację materiałów- sprawdzenie jakości i kompletności dostaw zgodnie z zamówieniami oraz oznakowań, cechowania materiałów gatunkiem i wytopem.
- cięcie i ukosowanie mechanicznie lub gazowe zgodnie z rysunkami warsztatowymi i Instrukcjami Technologicznymi Spawania WPS.

- przenoszenie znaków materiałowych (gatunek, wytop) na wszystkie detale.

- oczyszczenie powierzchni z wszelkich zanieczyszczeń na szerokości min. $20 \mathrm{~mm}$ od spawanych krawędzi elementu.

- wykonanie spoin sczepnych zgodnie z kwalifikowaną technologią spawania, które podlegają w $100 \%$ badaniom VT.

- stosowanie płytek dobiegowych i wybiegowe przy złączach gdzie występują spoiny czołowe, które powinny być przygotowane tak jak materiał spawany.

- aktualizację i weryfikację uprawnień spawaczy wg PN-EN ISO 9606-1.

\section{Spawanie i kontrola podczas spawania obejmuje}

- wykonywanie prac spawalniczych zgodnie z planem spawania oraz instrukcją technologiczną WPS, zwracając uwagę aby spoiny pachwinowe były zamknięte.

- stosowanie podgrzewania wstępnego zgodnie z instrukcją technologiczną WPS wraz z kontrolą temperatury.

- oczyszczenie poszczególnych warstw spoiny z odprysków, żużla przed nałożeniem kolejnej warstwy oraz sprawdzenie temperatury międzyściegowej.

- nanoszenie trwale numerów spawacza lub operatora.

\section{Kontrola po spawaniu obejmuje}

- wykonanie pomiarów geodezyjnych potwierdzających prawidłowość wykonania konstrukcji

- wybór metody NDT przez osobę posiadającą uprawnienia stopnia 3 zgodnie z EN1 2062.

- wykonanie badań nieniszczących przez wykwalifikowany personel (stopień 2 zgodnie z PN-EN ISO 9712).

- usunięcie tymczasowych płyt dobiegowych i wybiegowych, śladów zajarzenia łuku, do powierzchni materiału podstawowego, a następnie przeprowadzenie $100 \%$ badań magnetycznych w celu wykrycia pęknięć.

W tablicy III przedstawiono plan badań dla dźwigara wiaduktu kolejowego.

\section{Wykonanie stołów montażowych}

$\mathrm{Na}$ podstawie dokumentacji technicznej poszczególnych torów stworzono schemat punktów podparć dźwigarów, który zawierał cztery dźwigary każdego toru. Każdy schemat zawierał w swoim zakresie wspólny dźwigar, czyli

Tablica I. Wykaz materiałów złącznych

Table I. A list of coupling materials

\begin{tabular}{|c|c|c|c|c|c|}
\hline \multicolumn{2}{|c|}{ Śruby } & \multicolumn{2}{c|}{ Nakrętki } & Podkładki \\
\hline M27 10.9 HV TZN & EN- 14399-4 & M27 10 HV TZN & EN- 14399-4 & 27 HV TZN & 14399-6 \\
\hline M24 10.9 HV TZN & EN- 14399-4 & M24 10 HV TZN & EN- 14399-4 & 24 HV TZN & $14399-6$ \\
\hline M20 10.9 HV TZN & EN- 14399-4 & M20 10 HV TZN & EN- 14399-4 & 20 HV TZN & $14399-6$ \\
\hline M42 8.8 & EN- 4014 & M42 8 & EN- 4032 & 42 & DIN 125 \\
\hline M20 8.8 & EN- 4014 & M20 8 & EN- 4032 & 20 200HV TZN & DIN 125 \\
\hline M16 8.8 & EN- 4014 & M168 8 & EN- 4032 & DIN 125 \\
\hline M12 8.8 & EN- 4014 & M12 8 & EN- 4032 & 12 & DIN 125 \\
\hline
\end{tabular}


Tablica I. Wykaz materiałów złącznych

Table I. A list of coupling materials

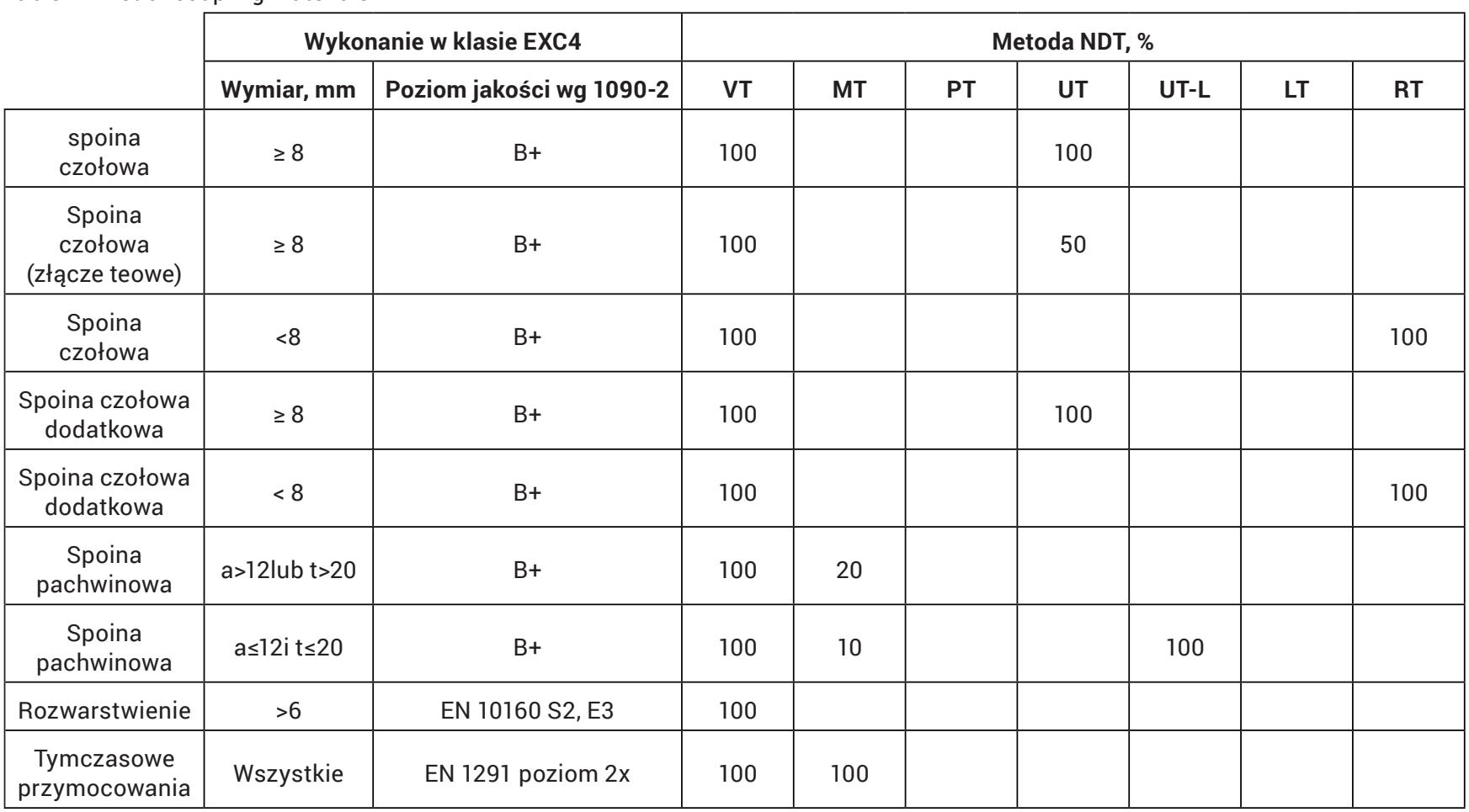

dla schematu pierwszego element końcowy będzie elementem pierwszym schematu drugiego. Podpory wykonano tak aby zapewnić stabilne i bezpieczne ustawienie konstrukcji oraz swobodne poruszanie się pod nią, w celu montażu i dokręcenia śrub. Fragment schematu punktów podparć przedstawiono na rysunku 5.

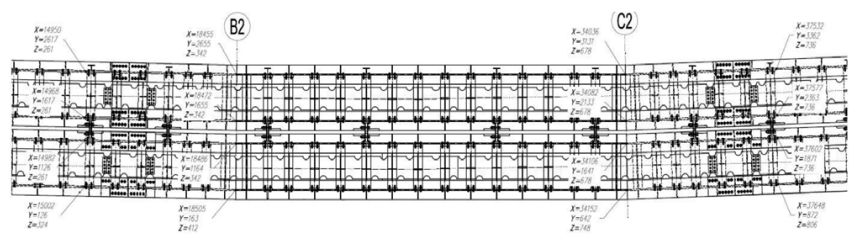

Rys. 5. Schemat usytuowania charakterystycznych punktów podparć na spodach dźwigarów

Fig. 5. An outline of placing specific support points at the bottom of girders.

\section{Kolejność spawania}

Kolejność spawania obejmuje:

- wykonanie spoin czołowych belek głównych wzdłużnych HL1000x642. Spawanie należy rozpocząć od półek o grubości 60mm (rys. 6), a następnie środników o grubości $34 \mathrm{~mm}$ (rys. 7).

- użebrowanie belek głównych HL1000x642. Blachy o grubości $15 \mathrm{~mm}$ i $10 \mathrm{~mm}$ łączymy z belkami głównymi spoinami pachwinowymi dwustronnymi odpowiednio $a=6 \mathrm{~mm}$ i $a=4 \mathrm{~mm}$.

- wykonanie płyty pod belki poprzeczne HEB200 z blachy $\neq 10 \mathrm{~mm}$. Spawanie spoin czołowych, a następnie pachwinowych narożnych dwustronnych $a=4 \mathrm{~mm}$. Połączenie śrubami płyty z belkami głównymi HL1000x642.

- spawanie żeber do belek poprzecznych HEB200 w punktach krzyżowania się osi szyny z osiami tych belek, prostopadle do ich środników spoinami pachwinowymi dwustronnymi a $=6 \mathrm{~mm}$.

- próbny montaż belek poprzecznych HEB200 wraz ze stopami do belek głównych wzdłużnych i płyty, tak aby otwory pod połączenia śrubowe były zgodne. Następnie demontaż, spawanie belek poprzecznych HEB200 ze stopami (blacha o gr. $30 \mathrm{~mm}$ ) spoinami pachwinowymi $\mathrm{a}=6 \mathrm{~mm}$

- spawanie stóp belek poprzecznych HEB200 z belkami głównymi wzdłużnymi. Spoinę pachwinową a=10 o długości 100mm należy spawać w pozycji PF.

- Spawanie blach- przepon do belek głównych w miejscach podpór spoiną pachwinową obustronną $\mathrm{a}=8 \mathrm{~mm}$.

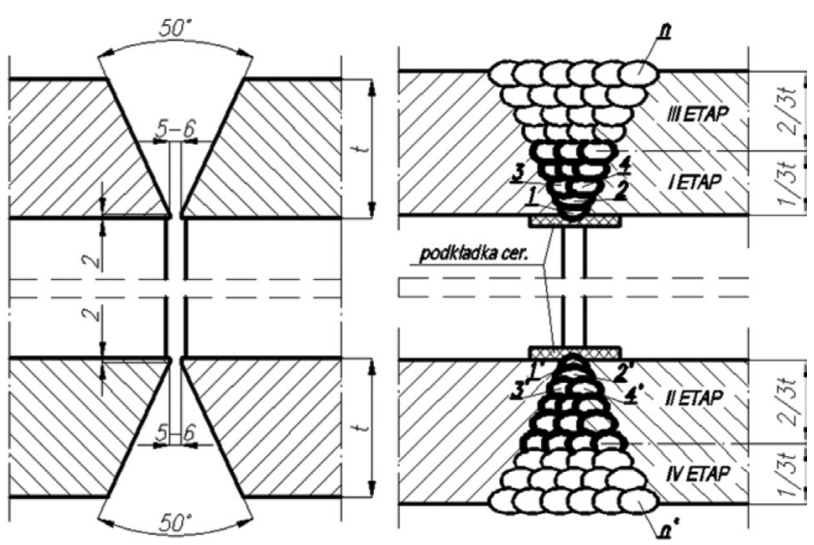

Rys. 6. Przygotowanie oraz kolejność spawania pasów HL1000x642 Fig. 6. Preparation and order of welding HL1000x642 flanges

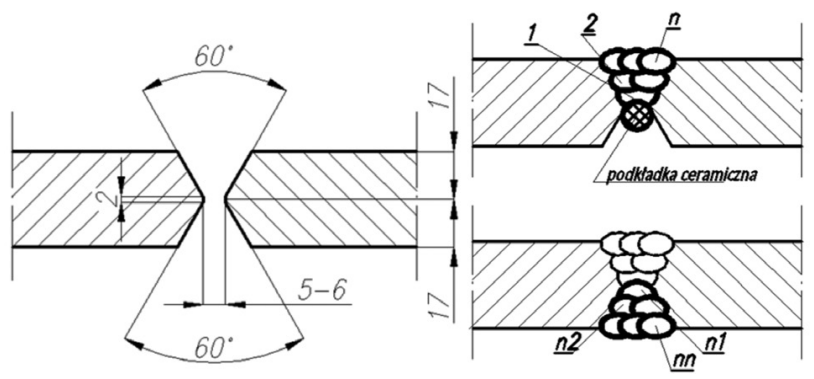

Rys. 7. Przygotowanie oraz kolejność spawania środnika HL1000x642

Fig. 7. Preparation and order of welding HL1000x642 web 


\section{Dokumentacja końcowa}

Dokumentacja końcowa powinna zawierać:

- świadectwa jakości materiałów podstawowych,

- świadectwa jakości śrub, nakrętek i podkładek

- świadectwa jakości materiałów dodatkowych

- protokoły z badań nieniszczących
- certyfikaty personelu NDT

- rejestr spawaczy wraz z aktualnymi uprawnieniami

- Instrukcje Technologiczne Spawania WPS wraz z WPQR

- dzienniki spawania

- raporty kontroli kształtu i wymiarów, potwierdzające wymaganą tolerancję z próbnego montażu wszystkich dźwigarów

\section{Podsumowanie}

Konstrukcja dźwigarów wykonano zgodnie z najwyższymi wymaganiami, o skomplikowanej technologii (wykonanie kilkudziesięciu tysięcy otworów, montaż, kolejność spawania itp.). Dzięki urządzeniom CNC zachowano powtarzalność parametrów, a tym samym uzyskano odpowiednią jakość powierzchni wg EN ISO 9013. Bardzo wysokie wymagania jakościowe stawiane przez normę dotyczącą wykonania konstrukcji stalowych PN-EN 1090-2-klasa EXC 4 wymuszają na całym pionie technologicznym oraz warsztacie wysokie kwalifikacje, precyzję oraz dbałość o właściwą jakość produktu [1 $\div 18]$.

\section{Literatura}

[1] Słania J.: Skóra J.: Plan spawania wymiennika ciepła chłodzonego powietrzem Przegląd spawalnictwa nr 2/2011,str. 19-26.

[2] Słania J.: Plany spawania. Teoria i praktyka. Agenda Wydawnicza SIMP, Warszawa 2013

[3] Słania J.: Plan technologiczny spawania płyty gąsienicowej. Przegląd Spawalnictwa, 2010, nr 3, str. 16-25.

[4] Słania J., Kaczor T.: Plan spawania zbiornika ciśnieniowego. Przegląd Spawalnictwa, 2010, nr 4, str. 9-18.

[5] Słania J., Kwiecień L., Jarosiński J.: Plan spawania kotłów płomienicowo - płomieniówkowych. Przegląd Spawalnictwa, 2010, nr 6, str 32-40.

[6] Słania J., Skóra J.: Plan spawania wymiennika ciepła chłodzonego powietrzem. Przegląd Spawalnictwa 2011, nr 2, str 16-22.

[7] Słania J.: Plan spawania carg płaszcza pieca obrotowego. Przegląd Spawalnictwa 2011, nr 2, str. 36-41.

[8] Słania J., Wodecki D.: Plan spawania belki poprzecznej dźwigu.Przegląd Spawalnictwa 2011, nr 2, str. 30-35.

[9] Słania J.: Istota planów spawania. Przegląd Spawalnictwa 2011, nr 2, str 3-9.

[10] Słania J.: Plan spawania napraw bieżących kotłów parowych, wodnych i stałych zbiorników ciśnieniowych. Przegląd Spawalnictwa 2011, nr 2, str 22-30
[1 1] Słania J., Kwiecień L., Jarosiński J.: Kotły płomienicowo - płomieniówkowe - plan spawania oraz kontroli i badań. Dozór Techniczny 2011, nr 2, str. $35-41$.

[12] Słania J., Chomiuk S., Dadak R.: Plan spawania dla konstrukcji uzupełniającej - trawresy. Przegląd Spawalnictwa 2012, nr 2, str 3-6.

[13] Stania J., Marcinkiewicz H., Kiełbik M.: Plan spawania elementu obudowy kopalnianej - osłony odzawałowej. Przegląd Spawalnictwa 2012, nr 2, str. 6-16.

[14] Słania J., Fryc H.: Spawanie pojazdów szynowych - plany spawania. Przegląd Spawalnictwa 2012, nr 2, str. 16-20.

[15] Słania J.: Plan spawania stalowej kładki dla pieszych I. Przegląd Spawalnictwa 2012, nr 2, str. 20-24.

[16] Słania J.: Plan spawania stalowej kładki dla pieszych II. Przegląd Spawalnictwa 2012, nr 2, str. 24-26.

[17] Słania J., Urbańczyk P.: Technologia wytwarzania oraz plan kontroli jakości przegrzewacza pary kotła parowego wg PN-EN 12952-5. Przegląd Spawalnictwa 2012, nr 5, str. 29-41.

[18] Chromik D., Słania J.: Plan spawania ciśnieniowego zespołu rurowego. Przegląd Spawalnictwa 2012, nr 11, str. 29-32. 